\title{
Late-term Effects of Surgery on Nasal Functions in Patients who Underwent Total Laryngectomy Surgery
}

\author{
Deniz Karaoglu ${ }^{1}$ Murat Kocyigit ${ }^{2}$ Safiye Giran Ortekin ${ }^{2}$ Mustafa Kemal Adali ${ }^{3}$ \\ ${ }^{1}$ Department of Otolaryngology, Inegol State Hospital, Bursa, Turkey \\ 2 Department of Otolaryngolgy, Istanbul Kanuni Sultan Suleyman \\ Address for correspondence Murat Kocyigit, MD, Department of \\ Otolaryngolgy, Istanbul Kanuni Sultan Suleyman Egitim ve Arastirma \\ Hastanesi, Istanbul Kanuni Sultan Suleyman Egitim ve Arastirma \\ Egitim ve Arastirma Hastanesi Ringgold Standard Institution, \\ Istanbul, Turkey
}

${ }^{3}$ Department of Otolaryngology, Bir Nefes Private Hospital, Edirne, Luleburgaz, Turkey

Int Arch Otorhinolaryngol 2017;21:270-275.

\begin{abstract}
Introduction There is a common opinion that losing airway functions in total laryngectomy patients cause changes in nasal physiological rates. Studies conducted to review the subject present gaps, especially in terms of objective measurements.

Objective We evaluated late-term effects of surgery on nasal functions in patients who underwent total laryngectomy surgery more than two years ago.

Methods We included in the study 22 patients who had undergone total laryngectomy, as well as 24 healthy subjects with similar demographic characteristics as the control group. We performed acoustic rhinometry for intranasal volume and cross-sectional area measurements, saccharin test for measurement of nasal mucociliary clearance, and smell identification test for evaluation of olfactory function in the patient and control groups. We compared and statistically analyzed the data obtained from the groups.

Results In our study, although late-term ( $>2$ years) measurements were not statistically significant, we detected more nasal passage patency in the patient group than in the control group. In smell identification test, lower scores were obtained in the patient group. The difference between measurements in both groups was statistically significant.

Keywords

- laryngectomy

- rhinometry

- mucociliary clearance

- olfactory Conclusion We believe that since the upper respiratory tract is disabled due to tracheostomy in patients with total laryngectomy, atrophy occurs in the late term and, consequently, nasal mucociliary clearance is impaired. We also see diminished olfactory function in total laryngectomy patients.
\end{abstract}

\section{Introduction}

Total laryngectomy is a common treatment in advanced larynx cancers. Nowadays, total laryngectomy inductions are restricted and are applied less frequently. This is largely a result of the development of partial laryngectomy and radiotherapy. In a total laryngectomy, removing the larynx

received

September 11, 2016

accepted

November 6, 2016

published online

January 4, 2017 causes dissociation of the digestive tract from the respiration tract and breaks down the vocal system. The patient cannot emit sound and the upper respiratory tract is inactive. After a laryngectomy, some defects appear in some functions such as swallowing, taste, and smell. Because of tracheostomy, breathed air ceases to connect with nasal mucous membrane and constitutional, short and long-term changes occur in the
Copyright @ 2017 by Thieme Revinter

Publicações Ltda, Rio de Janeiro, Brazil
License terms

() (1) $\Theta \circledast$ 
nasal mucous surface. ${ }^{1-3}$ The consensus is that losing airway functions in total laryngectomy patients causes changes in nasal physiological rates. ${ }^{3}$ Studies conducted to review the subject present gaps, especially in terms of objective measurements.

\section{Objective}

In our study, we have tried to obtain objective results by comparing with healthy volunteers, showing similar demographic characteristic with the laryngectomees in nasal ciliary activity, the measurements of intranasal volume and the olfactory functions to evaluate the functions of the nose, physiological airway, at post laryngectomy.

\section{Methods}

This study conducted with a control group included 24 healthy volunteer individuals and 22 patients operated for total laryngectomy. This study included patients whose surgical operation had been at least 2 years prior. Individuals in both groups were men. The control group's average age was $60.32 \pm 9.87$ and the total laryngectomy performed group's average age was $60.32 \pm 8.82$. In the endoscopic exam, neither of the groups presented nasopharyngeal pathology. In the control group, 5 individuals had diabetic and 8 individuals were addicted to smoking. In contrast, patients that performed total laryngectomy were not diabetic and only one of them was addicted to smoking. We identified 11 patients with nasal septum deviation. Although all the individuals that were addicted to smoking continued smoking in the control group, 21 out of the 22 patients that underwent total laryngectomy gave up smoking. This study received approvalfrom the Ethics Board and written approval from patient and control groups (Approval Protocol Number: TÜTFEK-2006/ 059). We performed a smell recognition test for mucociliary clearance measurement, saccharin test ${ }^{4}$ for inner nasal volume, and cross-sectional area measurement. We conducted a smell recognition test for acoustic rhinometry ${ }^{5,6}$ and smell functions evaluation. $^{7}$

\section{Acoustic Rhinometry}

In this study we used a Rhinometrics SRE 2000 device, Rhinoscan version 2.5, Microsoft Windows 98 operating system, and Intel Pentium III 1.2 Ghz (133 9.0; RhinoMetrics, Denmark) computer system for acoustic rhinometry measurements.

The medium was soundless to take the most appropriate measurement. For participant adaptation to the media, the participant was provided the same media over $\sim 30$ minutes prior to the operation. The same researcher performed whole measurements.

We carried out postoperative measurements after at least two years. In both groups, we did not apply nasal decongestant before measurement. Before postoperative measurement at nasal cavity edema, we noted incrustation and secretion. Participants in the control group did not have stuffiness or any surgical operation history. In the nasal cavity exams such as rhinoscopy and, nasal endoscopy mucous had normal appearance.

We used four parameters in this study: minimal crosssection area 1 (MCA1) with $0.0 \mathrm{~cm}$ and $2.2 \mathrm{~cm}$ in the narrowest cross-section area to nasal cavity. The unit of measurement was $\mathrm{cm}^{2}$. Minimal cross-section area 2 (MCA2) was the narrowest cross-section between $2.2 \mathrm{~cm}$ and $5.5 \mathrm{~cm}$ with the unit of measurement in $\mathrm{cm}^{2}$. T vol is total volume to the nasal cavity between $0.0 \mathrm{~cm}$ and $5.4 \mathrm{~cm}$ and unit of measurement is $\mathrm{cm}^{3}$. MCA value is formed by the smallest of MCA1 and MCA2 values and expresses the narrowest area in the nasal cavity.

We evaluated nasal cavity participants separately. We performed statistical analysis on 44 nasal cavities of 22 patients and 48 nasal cavities of 24 individuals.

\section{Mucociliary Clearance Measurement}

We carried out the mucociliary clearance measurement with the participant in the upright sitting position. First, we cleaned all the individuals' nasal secretions. In the chosen cavity, we preferred sides that were not deviated. We placed a saccharin tablet with the dimensions of $1 \times 1 \times 1 \mathrm{~mm}(1 / 4$ saccharin tablet) with a $1 \mathrm{~cm}$ retreat from the medial surface front border. We asked participants to not sneeze or snuffle and to keep their head bent head low. They received instructions to swallow once every 30 seconds and to inform as soon as they tasted saccharin. The moment at which participants tasted saccharin was ntoed as the clearance duration.

\section{Smell Recognition Test}

Before starting this test, we asked participants whether they could perceive smell at all. All participants replied positively. We chose mostly odors that were known, taking into consideration the social and cultural context. We presented six pictures of sources of odors to participants using a printed A4 photographic paper. Participants then smelled six odors in bottles (coffee, garlic, vanilla, carnation, cinnamon, and rose water). The participants had to match the pictures with the odor in every bottle. We noted participants' correct definition, scoring, and numbers.

We performed statistical analysis using Minitab package program (S0064 Minitab Release 13) (License No: Wcp 1331.00197). We determined normal distribution congruities to measurable data through a sample Kolmogorov-Smirnov test. For intergroup comparison, we used the 'T' test in independent groups with individuals suitable for normal distribution. For individuals not suitable for normal distribution, we used the Mann-Whitney U test. For qualitative data, we used the Pearson $x^{2}$ analysis and Fisher's $x^{2}$ analysis. We provide the arithmetic means \pm SS for quantitative data and numbers and percentages for qualitative data. Significance level was set at $\mathrm{p} \leq 0.05$ for all statistical analyses.

\section{Results}

This study consisted of 22 patients with ages between 43 and 79 years and 24 people as the control group with ages between 44 and 79 years. All of them were men. There was 


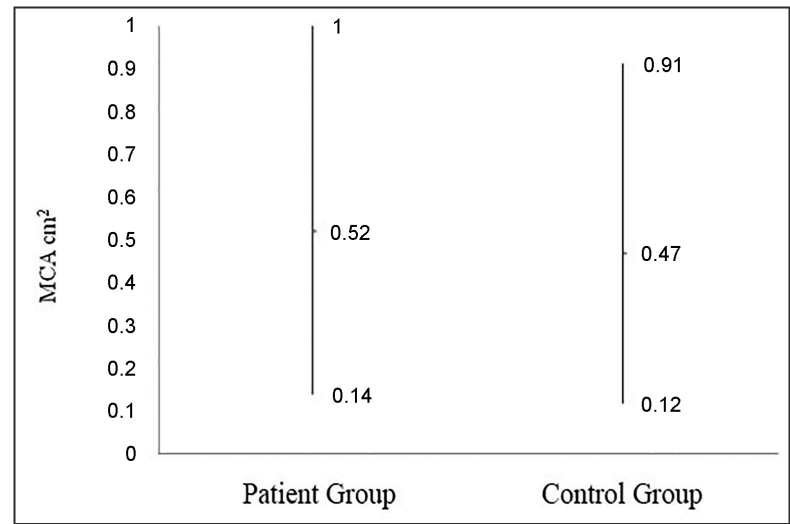

Fig. 1 Assessment of groups with minimum cross-sectional area values. MCA: Minimal Cross-sectional Area.

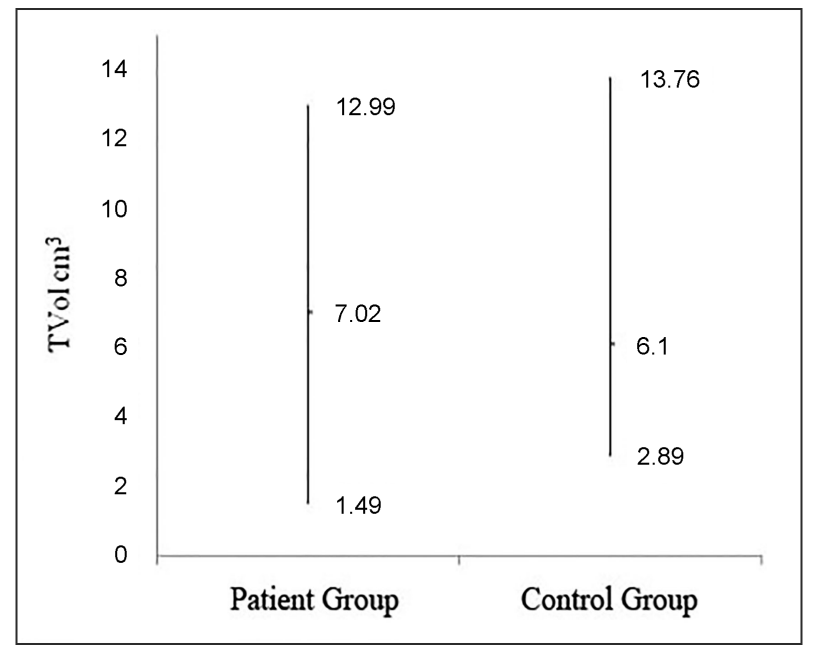

Fig. 2 Assessment of groups with mean total volume values. T Vol: Total Volume.

no difference between average ages in groups and the difference between ages was not significant $(p=0.186)$. We found no nasopharyngeal pathology through endoscopic assessment in either the patient or control group.

While all patients in the study group (22) presented larynx cancer symptoms, as they had been addicted to smoking, only 8 out of 24 men (33.3\%) were addicted to smoking in the control group. Only one individual in the patient group (4.54\%) and 8 (33.3\%) in the control group were smoking. Because of the smoke effect while evaluating nasal function results, individuals who were smoking did not undergo evaluation. Eleven men (50\%) out of the 22 in the patient group and 24 individuals of the $14(63.3 \%)$ in the control group had nasal septum deviation. Statistical difference was not significant between both groups deviation rates $(\mathrm{p}=0.571)$.

The MCA average measured $0.47 \mathrm{~cm}^{2}$ for the 48 nasal cavities in the control group and $0.52 \mathrm{~cm}^{2}$ for the 44 nasal cavities in the patient group ( $\mathbf{- F i g . 1}$ ). $\mathrm{T}$ Vol average was 6.10 $\mathrm{cm}^{3}$ for the control group and $7.02 \mathrm{~cm}^{3}$ the patient group (-Fig. 2). In terms of MCA and T Vol rates, the difference was not significant between the two groups $(p>0.05)(-$ Table 1$)$.

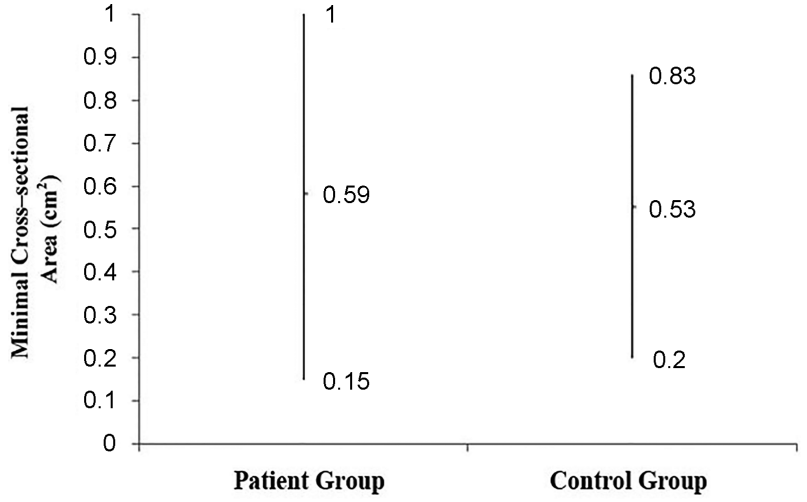

Fig. 3 Assessment of subjects without nasal septum deviation, diabetes, and non-smoker in terms of minimal cross-sectional area.

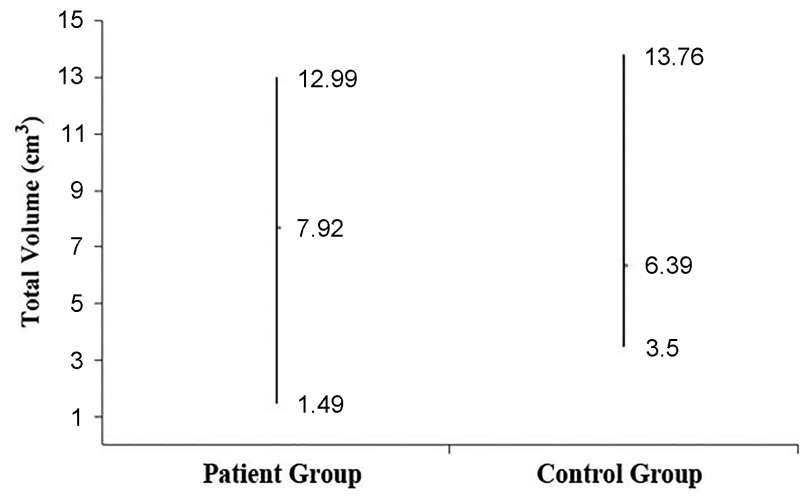

Fig. 4 Assessment of subjects without nasal septum deviation, diabetes, and non-smoker in terms of total volume.

For the purpose of ruling out some changes appearing at the nose that caused smoke and diabetes, septum deviation, nasal septum deviation's MCA and TVol rates were compared with 6 individual $(25 \%)$ in the control group, 10 individual (45.4\%) in the patient group which did not have smoke and diabetes.

We determined MCA average for 12 nasal cavities as 0.53 $\mathrm{cm}^{2}$ and for 20 nasal cavities as $0.59 \mathrm{~cm}^{2}$ in control and patient groups, respectively, where as T Vol average was 6.39 $\mathrm{cm}^{3}$ and $7.92 \mathrm{~cm}^{3}$, respectively (-Figs. 3 and 4). The difference between T Vol and MCA measurements was not significant $(p>0.05)(-$ Table 2$)$.

We compared 13 individuals (54.16\%) in the control group (24) and 21 individuals (95.4\%) in the patient group (22) with each other for mucociliary clearance time in the saccharin test. Mucociliary clearance time average was 662.5 seconds for the 13 men in the control group and 1017.14 seconds for the 21 men in patient group ( - Fig. 5). The difference between mucociliary clearance times was significant $(\mathrm{p} \leq 0.05)$.

We compared all men in both groups for smell recognition. While the control group volunteers could distinguish an average of 4.92 (82\%) out of the 6 scents, the average for the patient group was $2.82(47 \%)$ in the patient group (-Fig. 6). The difference between smell recognition rates was significant $(\mathrm{p} \leq 0.05)$. 
Table 1 Acoustic rhinometry measurements of the nasal cavity (mean values)

\begin{tabular}{|l|l|l|l|}
\hline & Patient group & Control group & $\mathbf{P}^{*}$ \\
\hline MCA cm & $0.52 \pm 0.23$ & $0.47 \pm 0.19$ & 0.350 \\
\hline TVol cm & $7.02 \pm 2.60$ & $6.10 \pm 2.05$ & 0.061 \\
\hline
\end{tabular}

Abbreviations: MCA, Minimal Cross-sectional Area; TVol, Total Volume. * Independent samples test ( $\mathrm{p}>0.05)$.

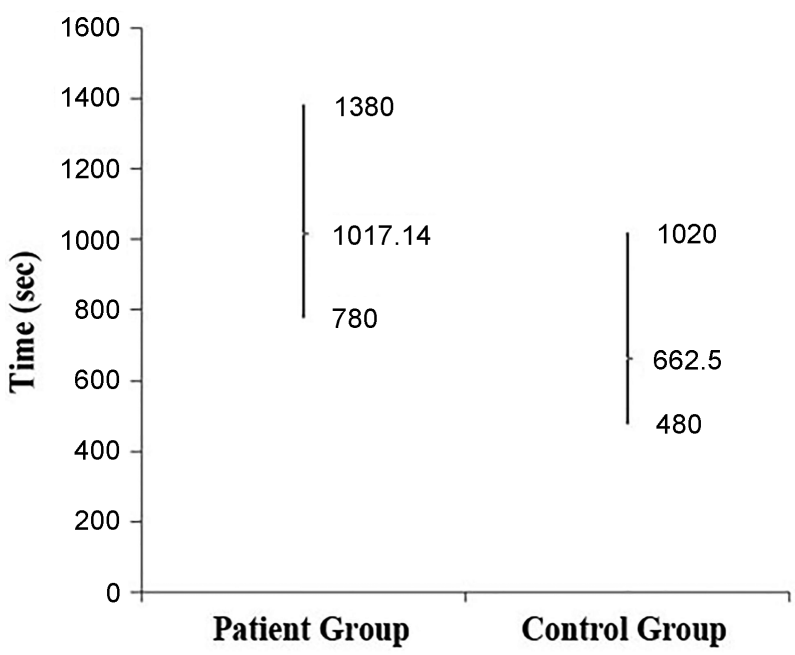

Fig. 5 Assessment of mean mucociliary clearance times between the groups.

The difference between control and patient groups in terms of smell recognition rates, except for carnation and rose water, was statistically significant ( - Table 3 ).

\section{Discussion}

There is a common belief that there is an alteration of physiological values in the noses of patients with total laryngectomy. ${ }^{2}$ However, there is a deficit in objective measurements among the studies focused on this subject. Our study aims to evaluate the functions of the nose as a physiologic airway after total laryngectomy operation.

Several studies measure physiology and nasal airway openness after total laryngectomy; however, such studies relied mostly on anterior rhinoscopy or rhinomanometry procedures. ${ }^{8-10}$ In our opinion, anterior rhinoscopy only is
Table 2 Acoustic rhinometry measurements of the nasal cavities in subjects without nasal septum deviation, diabetes, and non-smoker in terms of minimal cross-sectional area (mean values)

\begin{tabular}{|c|c|c|c|}
\hline & Patient group & Control group & $\mathbf{p}^{*}$ \\
\hline $\mathrm{MCA} \mathrm{\textrm {cm } ^ { 2 }}$ & $0.59 \pm 0.23$ & $0.53 \pm 0.19$ & 0.433 \\
\hline TVol $\mathrm{cm}^{3}$ & $7.92 \pm 2.93$ & $6.39 \pm 2.81$ & 0.157 \\
\hline
\end{tabular}

Abbreviations: MCA, Minimal Cross-sectional Area; TVol, Total Volum. * Independent samples test ( $\mathrm{p}>0.05)$.

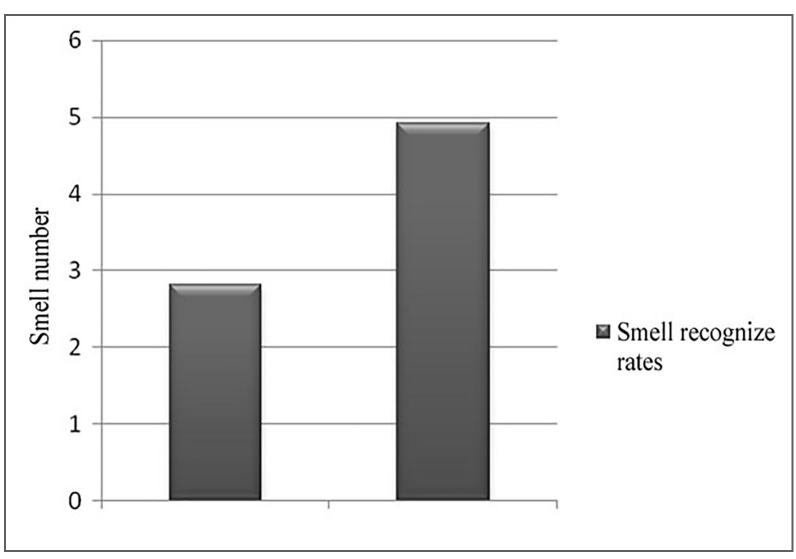

Fig. 6 Assessment of mean smell identification rates between the groups.

not efficient for such an assessment. Rhinomanometry is an assistive evaluation method for the nose assessment and it gives indirect information about hypertrophic or atrophic structures of the nose. ${ }^{9}$ Acoustic rhinomanometry is a quick, non-invasive, and reliable method to assess nasal cavities. ${ }^{11,12}$

There are a few acoustic rhinomanometry studies conducted in total laryngectomised patients. Ozgursoy and Dur$\operatorname{sun}^{13}$ used rhinomanometry to assess the nasal cavities in pre- and post-term total laryngectomy performed on 48 patients. They found that there was a contraction in the narrowest segment of the nasal cavity and total volume during the first and second year follow-up measurements compared with preoperative conditions. Results from our data anakysis showed that the narrowest segment of the nose and total volumes of the patient group were higher than

Table 3 Smell identification percentages by the type of odor in the control and patient groups

\begin{tabular}{|l|l|l|l|l|l|l|}
\hline & Coffee & Vanilla & Garlic & Carnation & Cinnamon & Rose water \\
\hline Control group & $24(100 \%)$ & $17(71 \%)$ & $24(100 \%)$ & $16(67 \%)$ & $17(71 \%)$ & $20(83 \%)$ \\
\hline Patient group & $10(45 \%)$ & $9(41 \%)$ & $18(82 \%)$ & $9(41 \%)$ & $2(9 \%)$ & $14(64 \%)$ \\
\hline $\mathrm{P}^{*}$ & 0.001 & 0.042 & 0.029 & 0.083 & 0.001 & 0.134 \\
\hline
\end{tabular}

${ }^{*}$ Independent samples test $(\mathrm{p} \leq 0.05)$. 
that of the control group. But the difference was not statistically significant ( $\mathrm{p}>0.05$ ).

To exclude several alterations in the nose related to smoking and diabetes, we compared the MCA and T Vol values of 10 participants in the patient group and 6 participants in the control group without nasal septum deviation, who did not have diabetes and did not smoke. In our data analysis, the difference in the measurements between the patients and the control groups was also not statistically significant $(\mathrm{p}>0.05)$. In both groups, when we compared the measurements, the passage openness in the patient group was more than that of the control group. Although this reflected the delayed effects of total laryngectomy in the nose, we evaluated it as a reflection of atrophic changes as a result of not using the nose.

Mucociliary clearance is the most important protection mechanism of the nasal respiratory epithelium. Mucociliary functions indicate differences in environmental temperature, humidity, partial oxygen pressure $\left(\mathrm{PO}_{2}\right), \mathrm{pH}$, trauma, and inhaler agents such as sulfuric acid, formaldehyde, ozone, chlorine, smoke, ${ }^{14,15}$ chronic bronchitis, as well as anatomical obstacles such as septum deviation and diabetes mellitus. $^{16-18}$ In the present study, we excluded the diabetic and smoking participants in the control group for evaluation. To exclude the potential effects of age on mucociliary clearance, we chose volunteers with ages similar to those in the patient group to create our control group.

The interruption of airflow in the nasal cavity leads to changes in endonasal temperature, ${ }^{19}$ an increase in humidity, ${ }^{20}$ and changes in mucus consistency. Such changes give rise to the formation of a hyper-secretory phase and mucociliary clearance increases $^{21}$ in the early term, depending on the loss of nasal cycle, and a slowing down of the endonasal blood flow. ${ }^{22}$ We also determined in our study prolonged mucociliary clearance time in patients who underwent total laryngectomy at least two years ago. None of the studied cases presented mucociliary clearance time within pathological limits. The average mucociliary clearance time was $16.95 \pm 2.47$ minutes in the patient group; whereas in the control group, that average was $11.04 \pm 2.71$ minutes. Mucociliary clearance time of the patient group was significantly higher than the control group in our statistics $(p<0.01)$. We found that nasal mucociliary clearance slowed down in the later term, which is different from the results of previous studies conducted early ( $<2$ years) in patients with total laryngectomy. It is possible that there was damage to patients' nasal mucociliary clearance due to the disabling of the upper airway after total laryngectomy because of tracheostomy and due to atrophy of the nasal mucosa in the late stages. Mucociliary clearance time is prolonged because of the changes in the nasal mucosa in the chronic term. Moreover, such changes create conditions that favor secondary infections from saprophytic bacteria and cause atrophy in nasal mucosa, reduction in humidity, and a decrease in endonasal temperature.

Previous studies on patients with hyposmia-anosmia in the post-laryngectomy period considered there was a damage in the neuronal interaction between the nose and the larynx. ${ }^{8,23}$ Several studies evaluate olfactory activities in patients with total laryngectomy. Fujii et $\mathrm{al}^{24}$ used an olfactometer to assess preoperative and postoperative values at 3, 6, and 12 months in 29 patients with total laryngectomy. They found no statistically significant difference between preoperative and postoperative values. Leon et al's ${ }^{25}$ study was performed with 36 patients with total laryngectomy, scoring patients' smell recognition ratio. Comparing patients with total laryngectomy and a control group, their results were 2.9 and 6.6 points, respectively, out of a maximum of 10 points. The authors also explained odor disfunction with the lack of ventilation in the nasal mucosa. Risberg et $\mathrm{al}^{26}$ conducted a study with 24 patients and determined that 10 of those patients could smell and 14 could not smell after the fifth month post-laryngectomy. They associated the smell disfunction with not using the nose, which is the physiological airway. Hilgers et $\mathrm{al}^{27}$ supported the same association.

In our study, we assessed 24 participants in the patient group and 22 participants in the control group with the smell recognition test. While control group patients recognized a mean of 4.92 odors out of $6(82 \%)$, that mean was $2.82(47 \%)$ in the patient group. There was a statistically significant difference between the patient and control groups in terms of aromatic odors, such as coffee and cinnamon ( $\mathrm{p} \leq 0.05)$. While odor recognition ratio was determined in the control group for coffee, vanilla, garlic, and cinnamon as $100 \%, 71 \%$, $100 \%$, and $71 \%$, respectively, it was $45 \%, 41 \%, 82 \%$, and $9 \%$ in the patient group. We analyzed coffee, vanilla, garlic, and cinnamon data obtained from study groups and found statistically significant differences between them ( $\mathrm{p} \leq 0.05$ ), but the difference between carnation and rose water smells was not significant $(\mathrm{p}>0.005)$. Regarding carnation and rose water results, the control group was superior to the patient group. Odor recognition ratio for carnation and rose water smells in the control group were $67 \%$ and $83 \%$, whereas for the patient group were $41 \%$ and $64 \%$. The difference between the patient and control groups in terms of the general smell measurements was statistically significant $(p=0.001)$. In our opinion, loss of smell function in patients with total laryngectomy in our study is associated with not using the nose, which is the normal physiological airway, due to airway changes in post-laryngectomy.

\section{Conclusion}

Our results show some implication for late term effects of total laryngectomy on nose functions followed by an increase in the minimal sectional area, increase in total volume, a slowdown in ciliary flow, and reduction in recognizing odor and changes, which point out potential mucosal atrophy.

Based on the findings of our study, we believe it may be helpful to suggest nasal irrigation and moisturizing sprays to such patients to maintain the function and mucous membrane of the nose.

It is important to dedicate effort in providing the sense of smell in patients with total laryngectomy to improve both their safety and quality of life. For this purpose, it may be useful to develop new techniques to provide smell sense in 
patients with total laryngectomy and instruct the patients about available or future methods.

\section{References}

1 Maurizi M, Paludetti G, Almadori G, Ottaviani F, Todisco T. Mucociliary clearance and mucosal surface characteristics before and after total laryngectomy. Acta Otolaryngol 1986;102(1-2): 136-145

2 Moore-Gillon V. The nose after laryngectomy. J R Soc Med 1985; 78(6):435-439

3 Castellanos PF, Spector JG, Kaiser TN. Larenks ve larengofarenksin tümörleri (çeviri: M. Toprak). Şenocak D (Editor). Ballenger, Otorinolaringoloji baş ve boyun cerrahisi'nde. İstanbul: Nobel Tip Kitabevleri; 2000:585-652

4 Lale AM, Mason JD, Jones NS. Mucociliary transport and its assessment: a review. Clin Otolaryngol Allied Sci 1998;23(5): 388-396

5 Miman MC. Akustik rinometri: Kullanımı, endikasyonları, sınırları. KBB İhtisas Dergisi 2001;8:416-423

6 Hilberg O. Objective measurement of nasal airway dimensions using acoustic rhinometry: methodological and clinical aspects. Allergy 2002;57(Suppl 70):5-39

7 Richard LD, Steven MB, Windolyn DP. Olfactory function and dysfunction. In: Bailey BJ, Johnson JT, Newlands SD(Eds.). Head \& Neck Surgery-Otolaryngology. $4^{\text {th }}$ ed. Vol. 1, Philadelphia: Lippincott Williams \& Wilkins; 2006:289-306

8 Henkin RI, Larson AL. On the mechanism of hyposmia following laryngectomy in man. Laryngoscope 1972;82(5):836-843

9 Fisher EW, Liu M, Lund VJ. The nasal cycle after deprivation of airflow: a study of laryngectomy patients using acoustic rhinometry. Acta Otolaryngol 1994;114(4):443-446

10 Havas TE, Cole P, Gullane PJ, Kassel R, Kamino D. The nasal cycle after laryngectomy. Acta Otolaryngol 1987;103(1-2):111-116

11 Cakmak O, Celik H, Ergin T, Sennaroglu L. Accuracy of acoustic rhinometry measurements. Laryngoscope 2001;111(4 Pt 1): 587-594

12 Mamikoglu B, Houser SM, Corey JP. An interpretation method for objective assessment of nasal congestion with acoustic rhinometry. Laryngoscope 2002;112(5):926-929

13 Ozgursoy OB, Dursun G. Influence of long-term airflow deprivation on the dimensions of the nasal cavity: a study of laryngecto- my patients using acoustic rhinometry. Ear Nose Throat J 2007; 86(8):490-492

14 Dalhamn T. The effect of cigarette smoke on ciliary activity in the upper respiratory tract. AMA Arch Otolaryngol 1959;70(2): 166-168

15 Wanner A, Hirsch JA, Greeneltch DE, Swenson EW, Fore T. Tracheal mucous velocity in beagles after chronic exposure to cigarette smoke. Arch Environ Health 1973;27(6):370-371

16 Yue WL. Nasal mucociliary clearance in patients with diabetes mellitus. J Laryngol Otol 1989;103(9):853-855

17 Ho JC, Chan KN, Hu WH, et al. The effect of aging on nasal mucociliary clearance, beat frequency, and ultrastructure of respiratory cilia. Am J Respir Crit Care Med 2001;163(4):983-988

18 Mortensen J, Lange P, Nyboe J, Groth S. Lung mucociliary clearance. Eur J Nucl Med 1994;21(9):953-961

19 Sakakura Y, Ukai K, Majima Y, Murai S, Harada T, Miyoshi Y. Nasal mucociliary clearance under various conditions. Acta Otolaryngol 1983;96(1-2):167-173

20 Dixon FW, Hoerr NL, McCALL JW. The nasal mucosa in the laryngectomized patients. Ann Otol Rhinol Laryngol 1949;58(2): 535-547

21 Bende M. Blood flow in human nasal mucosa after total laryngectomy. Acta Otolaryngol 1983;96(5-6):529-531

22 Maurizi M, Ottaviani F, Paludetti G, Almadori G, Zappone C. Adenoid hypertrophy and nasal mucociliary clearance in children. A morphological and functional study. Int J Pediatr Otorhinolaryngol 1984;8(1):31-41

23 Hoye RC, Ketcham AS, Henkin RI. Hyposmia after paranasal sinus exenteration of laryngectomy. Am J Surg 1970;120(4):485-491

24 Fujii M, Fukazawa K, Hatta C, Yasuno H, Sakagami M. Olfactory acuity after total laryngectomy. Chem Senses 2002;27(2):117-121

25 Leon EA, Catalanotto FA, Werning JW. Retronasal and orthonasal olfactory ability after laryngectomy. Arch Otolaryngol Head Neck Surg 2007;133(1):32-36

26 Risberg-Berlin B, Ylitalo R, Finizia C. Screening and rehabilitation of olfaction after total laryngectomy in Swedish patients: results from an intervention study using the Nasal Airflow-Inducing Maneuver. Arch Otolaryngol Head Neck Surg 2006;132(3): 301-306

27 Hilgers FJ, van Dam FS, Keyzers S, Koster MN, van As CJ, Muller MJ. Rehabilitation of olfaction after laryngectomy by means of a nasal airflow-inducing maneuver: the "polite yawning" technique. Arch Otolaryngol Head Neck Surg 2000;126(6):726-732 